\title{
Enhanced Performance of Indirect Vector Controlled Induction Motor Drive with a Modified Type 2 Neuro-Fuzzy Torque Controller in Interfacing with dSPACE DS-2812
}

\author{
Repana Ramanjan $\operatorname{Prasad}^{1,2^{*}}$, Gadwala Durgasukuamar $^{3}$ \\ ${ }^{1}$ Department of Electrical and Electronics Engineering, VFSTR University, Vadlamudi, Guntur 522213, India \\ ${ }^{2}$ Department of Electrical and Electronics Engineering, VITS, Hyderabad 508284, India \\ ${ }^{3}$ Department of Electrical and Electronics Engineering, Vignan Institute of Technology and Science, Hyderabad 508284, India
}

Corresponding Author Email: prasad243@gmail.com

https://doi.org/10.18280/jesa.540203

Received: 20 August 2020

Accepted: 13 March 2021

\section{Keywords:}

PI controller, indirect vector control (IVC), induction motor drive (IMD), type 2 Neurofuzzy controller (T2NFC), type 1 neuro-fuzzy controller, foot print of uncertainty (FOU), induction motor (IM), member ship functions $(M F s)$

\begin{abstract}
Due to the nonlinearities of the PI controller, the performance of the PI controller is not satisfactory. The gains must be properly selected after changes in control parameters is one of the issues of the PI controller. The modified type 2 Neuro-Fuzzy torque controller of indirect vector control-based induction motor drive is proposed in this paper by taking single input as an error i.e. speed and torque against two inputs error and change in error of conventional T2NFC.The superiority of fuzzy and neural networks has been utilized by T2NFC as type 2 MF's consist of fuzzy and FOU. The intersection point of the membership function is smaller so that the value of the centroid method is more precise than the T1NFC. The induction motor parameters, such as stator phase current, speed, and torque of the proposed T2NFC are simulated in MATLAB at different operating conditions and compared with PI, T1NFC controllers. The proposed T2NFC significantly minimizes the ripples in torque of the induction motor in comparison with PI and T1NF controllers. The practical implementation is also carried out with a $3.7 \mathrm{KW}$ induction motor using DSP 2812 controller to analyse induction motor parameters in real-time.
\end{abstract}

\section{INTRODUCTION}

Induction motors are often used globally as the work-horse in most of the industrial and home applications. These motors are popular due to its reliability, easy installation, controlling and adaptability for many processes. A frame work is presented by Harnefors [1] for designing and analysing generalised rotor flux-oriented vector control system based on reduced order observer, moreover it address low speed sensor less operation. A filed oriented control is implemented using the rotor model in field coordinates using standard hardware microcontroller [2, 3].

The genetic algorithms are proposed by Krishnan [4] to solve nonlinearities of induction motor. Furthermore, when using a large number of population and iterations, the best results have been achieved which causes genetic algorithm requires more time for execution. By using Fuzzy PI control, the SVPWM based speed control of indirect vector-controlled induction motor drive was demonstrated in the ref. [5]. An Adaptive Neuro-Fuzzy based current controller was proposed by Durgasukumar and Pathak [6] to minimise the ripples in torque of IVC VSI fed IMD. The performance of the inverter is compared with conventional, neuro-fuzzy, and neural based SVM has been presented [7, 8].

The T2NFC controllers in the IVC are replaced with PI controller to improve the performance of the induction motor [9]. A new control approach of induction motor drive using a neuro-fuzzy speed controller under different operating conditions, such as steady-state, dynamic conditions, etc. has been presented [10, 11]. Adaptive control scheme and nonlinear based novel T2NF speed controller are proposed to reduce ripples in speed of the rotor, stator phase current and torque of an induction motor [12]. The Space Vector Modulation for two level inverter fed induction motor drive using type 2 fuzzy logic is presented in the ref. [13]. The performance comparison is made using PIDTC and F2DTC of IMD under different operating conditions, such as starting, steady-state, step change in load, etc has been presented [14, 15], however F2DTC gives better performance but it is difficult to implement as compare to conventional controllers. The development of a new T2NFC is to identify time variant methods and equalize time variant channels with clustered and gradient descent algorithms has been presented [16]

Further, hybrid neuro-fuzzy control (NFC) technique is applied in control system to overcome the drawback of fuzzy system and neural network while handling the IM as adjustable speed drive. However, some industries are still unwilling to use this controller as large computational burden is imposed by more membership functions (MFs), rules, particularly for self-tuning condition. The large sampling time because of high computational burden is not preferred for realtime industrial applications as it produces greater torque ripple [17, 18].

In this research paper proposes a modified T2NFC, which is a new tool with three dimensional fuzzy sets and foot print of uncertainty to provide the additional degrees of freedom and to develop the novel model for handling the uncertainty parameters of the drive at various load conditions.

Hence, the key focus area of this paper is to design and implement robust speed and torque compensator for an induction motor drive, that is computationally less burdened and can exhibit optimized performance.The proposed controller performance is investigated at all dynamic 
conditions both in simulation and experimentally.

\section{MATHEMATICAL MODELLING OF IM}

A dynamic model of the machine which is valid for any instantaneous variation of voltage and current and adequately describing the performance of the machine under starting, steady state and transient state operating conditions can be obtained by representing the machine voltages and currents in terms of actual phase variables or in terms of two axis variables or using space phasor theory. The three-phase motor is a balanced load because of the absence of zero sequence components and therefore it is possible to represent variables of one phase in terms of the other two thereby reducing the total number of equations describing the system. Thus, in such a model, a three-phase machine is replaced by an equivalent two-phase model with the both phases in quadrature. This helps in eliminating the mutual coupling that exists among the stator phases and rotor phases. The time varying self and mutual inductances can be made constant by referring all the variables to a common reference frame [3].

This common reference frame can be of two types i.e.

i). fixed to stator;

ii). fixed to rotor or fixed to the synchronously rotating magnetic field.

The realization of a variable frequency asynchronous motor drive with the high performance comparable to that of a separately excited DC motor requires a suitable mathematical model. The dynamic model of asynchronous motor drive will be useful in estimating the flux of the motor to determine the torque angle, the phase difference between the flux axes. And the stator current vector to fix up the flux axis and to enable the stator current to decompose into two components, i.e. one along with the flux axis and the other perpendicular to the flux axis. Basically, asynchronous motor can be seen as a transformer with a moving secondary, where the coupling coefficients between the stator and rotor phases change continuously with the change of rotor position $\omega_{R}$.

The machine model can be described by differential equations with time varying mutual inductances, but such a model tends to be very complex. In order to minimize the complexity, the machine in three phase quantities can be represented as an equivalent machine in two phase quantities. Even though it is made simple, the problem of time varying quantities still persists. Hence, the required quantities are referred to a common frame of reference and by doing so; the above problem is taken care of. Three different techniques have been proposed for referring the machine quantities to a common reference frame. The techniques proposed by Kron's method deals with referring quantities of stator and rotor, for a common synchronously rotating reference frame. This makes the motor parameters equivalent to that of a DC motor.

The mathematical modelling of a dynamic asynchronous motor drive is done with the following assumptions as:

The Voltage Source Inverter (VSI) fed model is used for estimating the flux linkages from voltages and currents and for simulating the motor for maintaining direct coupling between the inverter and the motor.

Stator and rotor flux linkages in terms of current can be expressed as:

Q-axis and D-axis stator flux linkage is given by:

$$
\lambda_{Q S}=L_{S} i_{Q S}+L_{M}\left(i_{Q S}+i_{Q R}\right)
$$

$$
\begin{gathered}
\lambda_{D S}=L_{S} i_{D S}+L_{M}\left(i_{D S}+i_{D R}\right) \\
\lambda_{Q R}=L_{R} i_{Q R}+L_{M}\left(i_{Q S}+i_{Q R}\right) \\
\lambda_{D R}=L_{R} i_{D R}+L_{M}\left(i_{D S}+i_{D R}\right) \\
\lambda_{D M}=L_{M}\left(i_{D S}+i_{D R}\right) \\
\lambda_{Q M}=L_{M}\left(i_{Q S}+i_{Q R}\right)
\end{gathered}
$$

where, $\lambda_{Q S}, \lambda_{Q R}, \lambda_{D S}, \lambda_{D R}$ are the $\mathrm{Q}$-axis and D-axis stator and rotor fluxes respectively. $\varphi_{Q M}, \varphi_{D M}$ are the mutual fluxes of $\mathrm{Q}$-axis and D-axis respectively. $L_{S}, L_{R}$ are the stator and rotor self inductances for respective axis. $L_{M}$ is the mutual inductance for respective axis of stator and rotor. $i_{Q S}, i_{Q R}$ are $\mathrm{Q}$-axis stator and rotor currents. $i_{D S}, i_{D R}$ are $\mathrm{D}$-axis stator and rotor currents.

Voltage equations from the Kron "s model by the stator field coils i.e. (DS and QS) with the armature coils i.e. (DR and QR). If the resistance $\mathrm{R}_{\mathrm{DS}}$, and total inductance $L_{D S}$ i.e. $\left(L_{D S}=\right.$ $\left.M_{D}+i_{D S}\right)$. It is manually coupled with the other $\mathrm{D}$-axis coil. The mutual inductance effect of the coil is considered in the voltage equation of DS circuit. Q-axis coil will have no effect on DS and no rotational voltages appear in it, since the coil DS is on stationary element.

Then the applied VDS voltage is as follows:

$$
V_{D S}=R_{D S} \cdot i_{D S}+L_{D S} p i_{D S}+M_{D} p i_{D R}
$$

Similarly, the applied voltage on Q-axis is identical to DS coil as:

$$
V_{Q S}=R_{Q S} \cdot i_{Q S}+L_{Q S} p i_{Q S}+M_{D} p i_{Q R}
$$

The rotational induced voltages in the armature DR and QR coils are as:

$$
V_{D R}=R_{D R} \cdot i_{D R}+L_{D R} p i_{D R}+M_{D} p i_{D S}-E_{D R}
$$

Negative sign for the rotational induced voltage $\left(E_{D R}\right)$ is due to neglecting of other voltage drops, then the induced voltage is equal and opposite to the applied voltage $\left(E_{D R}\right)$ as:

$$
E_{D R}=\omega_{R} \lambda_{Q}
$$

where, $E_{D R}=$ rotational induced voltage (emf) in volts, $\omega_{\mathrm{R}}=$ speed in rpm, $\lambda_{Q}=$ total armature flux linkages at $\mathrm{Q}$-axis in webers.

By substituting Eq. (10) in Eq. (9) we get is:

$$
V_{D R}=R_{D R} \cdot i_{D R}+L_{D R} p i_{D R}+M_{D} p i_{D S}-\omega_{R} \lambda_{Q}
$$

where, $\omega_{R}=\frac{d \theta}{d t}$ and $p=\frac{d}{d t}$.

Suffixes $\mathrm{S}$ and $\mathrm{R}$ represents stator and rotor respectively. $V_{D S}$ and $V_{Q S}$ are DQ axis stator voltages respectively, $i_{D S}, i_{Q S}$ and $i_{D R}, \mathrm{i}_{\mathrm{QR}}$ are $\mathrm{D}-\mathrm{Q}$ axis stator currents and rotor currents respectively. $R_{D S}, R_{Q S}$ and $R_{D R}, R_{Q R}$ are stator and rotor resistances per phase. $L_{D S}, L_{Q S}$ and $L_{D R}, L_{Q R}$ are self inductances of stator and rotor and $M_{D}, M_{Q}$ are mutual inductances. As we know that $\lambda_{Q}$ is the total armature flux linkage at Q-axis as: 


$$
\lambda_{\mathrm{Q}}=\mathrm{M}_{\mathrm{Q}}\left(\mathrm{i}_{\mathrm{QS}}+\mathrm{i}_{\mathrm{QR}}\right)+l_{Q R} \mathrm{i}_{\mathrm{QR}}
$$

Thus, we get $V_{D R}$ as:

$$
\begin{aligned}
\mathrm{V}_{\mathrm{DR}}=\mathrm{R}_{\mathrm{DR}} \cdot \mathrm{i}_{\mathrm{DR}}+ & \mathrm{L}_{\mathrm{DR}} \mathrm{pi_{ \textrm {DR } }}+\mathrm{M}_{\mathrm{D}} \mathrm{pi} \mathrm{i}_{\mathrm{DS}} \\
& -\omega_{\mathrm{R}} \mathrm{M}_{\mathrm{Q}}\left(\mathrm{i}_{\mathrm{QS}}+\mathrm{i}_{\mathrm{QR}}\right)-\omega_{\mathrm{R}} \mathrm{l}_{\mathrm{QR}} \mathrm{i}_{\mathrm{QR}} \\
\mathrm{V}_{\mathrm{DR}}=\mathrm{R}_{\mathrm{DR}} \cdot \mathrm{i}_{\mathrm{DR}}+ & \mathrm{L}_{\mathrm{DR}} \mathrm{pi}_{\mathrm{DR}}+\mathrm{M}_{\mathrm{D}} \mathrm{pi} \mathrm{i}_{\mathrm{DS}}-\omega_{\mathrm{R}} \mathrm{M}_{\mathrm{Q}} \mathrm{i}_{\mathrm{QS}} \\
& -\omega_{\mathrm{R}} \mathrm{L}_{\mathrm{QR}} \mathrm{i}_{\mathrm{QR}}
\end{aligned}
$$

i.e $L_{Q R}=M_{Q} l_{Q R}$.

Similarly,

$$
\begin{aligned}
V_{Q R}=R_{Q R} \cdot i_{Q R}+ & L_{Q R} p i_{Q R}+M_{Q} p i_{Q S}+\omega_{R} M_{Q} i_{D S} \\
& +\omega_{R} L_{D R} i_{D R}
\end{aligned}
$$

Then the matrix representations of the above equations are:

$$
\begin{gathered}
{\left[\begin{array}{c}
\mathrm{V}_{\mathrm{DS}} \\
\mathrm{V}_{\mathrm{QS}} \\
\mathrm{V}_{\mathrm{DR}} \\
\mathrm{V}_{\mathrm{QR}}
\end{array}\right]=} \\
{\left[\begin{array}{cccc}
\mathrm{R}_{\mathrm{DS}}+\mathrm{p} . \mathrm{L}_{\mathrm{DS}} & 0 & p \mathrm{M}_{\mathrm{D}} & 0 \\
0 & \mathrm{R}_{\mathrm{QS}}+\mathrm{pL}_{\mathrm{S}} & 0 & p \mathrm{M}_{\mathrm{Q}} \\
p \mathrm{M}_{\mathrm{D}} & \omega_{\mathrm{R}} \mathrm{M}_{\mathrm{Q}} & \mathrm{R}_{\mathrm{DR}}+\mathrm{p} \mathrm{L}_{\mathrm{DR}} & -\omega_{\mathrm{R}} \mathrm{L}_{\mathrm{QR}} \\
\omega_{\mathrm{R}} \mathrm{M}_{\mathrm{D}} & p \mathrm{M}_{\mathrm{Q}} & \omega_{\mathrm{R}} \mathrm{L}_{\mathrm{DR}} & \mathrm{R}_{\mathrm{QR}}+\mathrm{pL}_{\mathrm{QR}}
\end{array}\right]\left[\begin{array}{c}
\mathrm{i}_{\mathrm{DS}} \\
\mathrm{i}_{\mathrm{QS}} \\
\mathrm{i}_{\mathrm{DR}} \\
\mathrm{i}_{\mathrm{QR}}
\end{array}\right]}
\end{gathered}
$$

Three phase ac machine voltages can be directly transformed into two phase with the equivalent D-Q axis voltages, which are oriented at $\theta$ angle i.e. directly from $\mathrm{ABC}$ reference frame to the arbitrary frame by using the Park's transformation with respect to $\mathrm{Q}$ and $\mathrm{D}$-axis are as:

$$
\left[\begin{array}{l}
V_{A S} \\
V_{B S} \\
V_{C S}
\end{array}\right]=\left[\begin{array}{ccc}
\cos \theta & \sin \theta & 1 \\
\cos (\theta-120) & \sin (\theta-120) & 1 \\
\cos (\theta+120) & \sin (\theta+120) & 1
\end{array}\right]\left[\begin{array}{l}
V_{Q S 1} \\
V_{D S 1} \\
V_{O S 1}
\end{array}\right]
$$

where, $V_{A S}, V_{B S}, V_{C S}$, are three phase voltages and $V_{Q S 1}, V_{D S 1}$ are the stator Q-axis and D-axis voltages. $V_{O S 1}$ is the zerosequence component. By using the inverse relation, we get is:

$$
\left[\begin{array}{l}
V_{Q S 1} \\
V_{D S 1} \\
V_{O S 1}
\end{array}\right]=\frac{2}{3}\left[\begin{array}{ccc}
\cos \theta & \cos (\theta-120) & \cos (\theta+120) \\
\sin \theta & \sin (\theta-120) & \sin (\theta+120) \\
0.5 & 0.5 & 0.5
\end{array}\right]\left[\begin{array}{l}
V_{A S} \\
V_{B S} \\
V_{C S}
\end{array}\right]
$$

Two axis stationary reference frame is transformed into two axis rotating reference frame with the rotating speed " $\omega_{e}$ " with respect to stator D-Q axis. Then " $\theta_{e}$ " can be as:

$$
\theta_{e}=\omega_{e} t
$$

Two phase stator D-Q axis windings are transformed into hypothetical windings mounted on rotating D-Q axis. Then the rotating D-Q axis voltages are represented as:

$$
\begin{aligned}
& V_{Q S 2}=V_{Q S 1} \cos \theta_{e}-V_{D S 1} \sin \theta_{e} \\
& V_{D S 2}=V_{Q S 1} \sin \theta_{e}+V_{D S 1} \cos \theta_{e}
\end{aligned}
$$

where, $V_{Q S 2}, V_{D S 2}$ are the rotating $\mathrm{Q}$ and $\mathrm{D}$-axis voltages.

By transforming the rotor reference frame into stator reference frame, we get the 62 following voltages as:

$$
\begin{aligned}
& V_{Q S 1}=V_{Q S} \cos \theta_{e}+V_{D S} \sin \theta_{e} \\
& V_{D S 1}=V_{Q S} \sin \theta_{e}+V_{D S} \cos \theta_{e}
\end{aligned}
$$

So the three phase voltages are represented as:

$$
\begin{gathered}
V_{A}=V_{M} \cos W t \\
V_{B}=V_{M} \cos (W t-120) \\
V_{C}=V_{M} \cos (W t+120)
\end{gathered}
$$

where, $V_{A}, V_{B}, V_{C}$ are three phase stator reference phase voltages. Similarly, the current equations are represented as:

$$
\begin{gathered}
I_{A}=I_{M} \cos W t \\
I_{B}=I_{M} \cos (W t-120) \\
I_{C}=I_{M} \cos (W t+120)
\end{gathered}
$$

For balanced load, the zero-sequence voltage and current are absent. So, this helps to represent the three phase by an equivalent two phase machine. Then the stator phase voltages are expressed in the quadrature $\mathrm{D}-\mathrm{Q}$ axis as:

$$
\begin{aligned}
& V_{Q S}=R_{S} i_{Q S}+\omega_{\mathrm{e}} \lambda_{D S}+p \lambda_{Q S} \\
& V_{D S}=R_{S} i_{D S}+\omega_{\mathrm{e}} \lambda_{Q S}+p \lambda_{D S}
\end{aligned}
$$

where, $V_{Q S}, V_{D S}$ are stator D-Q axis voltages, $i_{Q S}, i_{D S}$ are stator D-Q axis currents, $R_{S}$ is the stator per phase resistance and, $\lambda_{D S}, \lambda_{Q S}$ are the stator D-Q axis flux linkages. Similarly, the rotor equations are given with the consideration of transformation angle for the rotor quantities i.e. $\left(\theta_{e}-\theta_{R}\right)$ as:

$$
\begin{aligned}
& V_{Q R}=R_{R} i_{Q R}+\left(\omega_{\mathrm{e}}-\omega_{R}\right) \lambda_{D R}+p \lambda_{Q R} \\
& V_{D R}=R_{R} i_{D R}-\left(\omega_{\mathrm{e}}-\omega_{R}\right) \lambda_{Q R}+p \lambda_{D R}
\end{aligned}
$$

where, $V_{Q R}, V_{D R}$ are rotor D-Q axis voltages, $i_{Q R}, i_{D R}$ are stator D-Q axis currents, $R_{R}$ is the rotor per phase resistance and, $\lambda_{D R}, \lambda_{Q R}$ are the rotor D-Q axis flux linkages.

The equation of the electromagnetic torque expressed in terms of the flux linkages and currents as:

$$
T_{e}=\frac{3 P}{2}\left[\lambda_{D R} i_{Q S}-i_{D S} \lambda_{Q R}\right]
$$

where, $T_{e}=$ Electro magnetic torque, $\lambda_{D R}=$ rotor flux linkage on $\mathrm{d}$ axis, $\lambda_{Q R}=$ rotor flux linkage on $\mathrm{q}$ axis.

\section{THE STRUCTURE OF INDIRECT VECTOR CONTROL}

The IVC is similar to that of DFOC apart from the unit vectors are obtained indirectly. The IVC technique phasor diagram, as shown in Figure 1. 


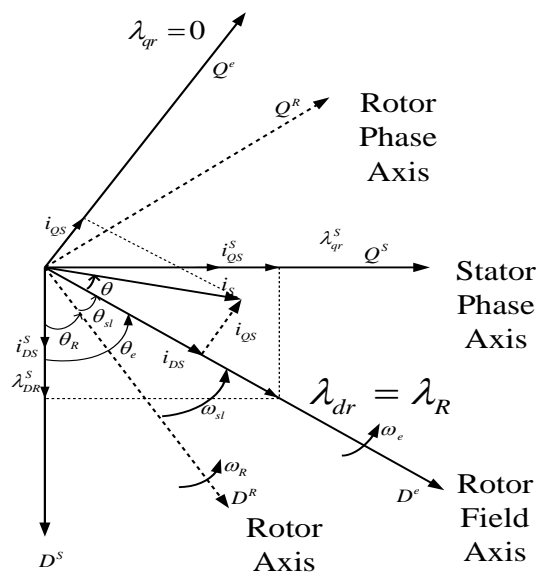

Figure 1. Indirect vector control phasor diagram

The rotor side equations of the induction motor containing flux linkages as variables are given by:

$$
\begin{aligned}
& 0=R_{R} i_{Q R}+p \lambda_{Q R}+\omega_{s l} \lambda_{D R} \\
& 0=R_{R} i_{D R}+p \lambda_{D R}+\omega_{s l} \lambda_{Q R}
\end{aligned}
$$

where,

$$
\begin{gathered}
\omega_{S l}=\omega-\omega_{R} \\
\lambda_{Q R}=L_{R} i_{Q R}+L_{M} i_{Q S} \\
\lambda_{D R}=L_{R} i_{D R}+L_{M} i_{D S}
\end{gathered}
$$

As the total rotor flux is aligned on d-axis, this leads to:

$$
\lambda_{Q R}=0, \lambda_{D R}=\lambda_{R} \text { and } p \lambda_{Q R}=0
$$

The new rotor equations are by substuting Eq. (40) in Eq. (35) and (36):

$$
\begin{aligned}
& 0=R_{R} i_{Q R}+\omega_{s l} \lambda_{R} \\
& 0=R_{R} i_{D R}+p \lambda_{D R}
\end{aligned}
$$

The rotor current interms of stator currents from Eq. (38) and (39):

$$
\begin{gathered}
i_{Q R}=-\frac{L_{M}}{L_{R}} i_{Q S} \\
i_{Q R}=\frac{\lambda_{R}}{L_{R}}-\frac{L_{M}}{L_{R}} i_{D S} \\
\omega_{S l}=\frac{L_{m} R_{R}}{\lambda_{R} L_{R}} i_{Q S}
\end{gathered}
$$

The fundamental principle of indirect vector control is derived by using the phasor diagram shown in Figure 2. In the diagram $d^{S}-q^{S}$ axes are fixed on the stator and the $d^{R}-q^{R}$ axes are fixed on the rotor, moving at speed $\omega_{R}$. Synchronously rotating axis $d-q$ is rotating ahead of the $d^{R}-q^{R}$ axes by the positive slip angle $\theta_{s l}$ corresponding to slip frequency $\omega_{s l}$.

From the phasor diagram,

$$
\begin{gathered}
\omega_{e}=\omega_{R}+\omega_{s l} \\
\theta_{e}=\int \omega_{e} d t=\int\left(\omega_{R}+\omega_{s l}\right) d t=\theta_{R}+\theta_{s l}
\end{gathered}
$$

The control equations of indirect vector control can be derived using the dynamic model of induction motor as discussed in the previous section. For decoupling control, the total rotor flux is aligned along the Rotor field d-axis; therefore, the q-axis rotor flux is zero.

The torque in indirect vector control can be expressed as:

$$
T_{e}=\frac{3}{2}\left(\frac{P}{2}\right) \frac{L_{m}}{L_{R}} \lambda_{D R} i_{S}
$$

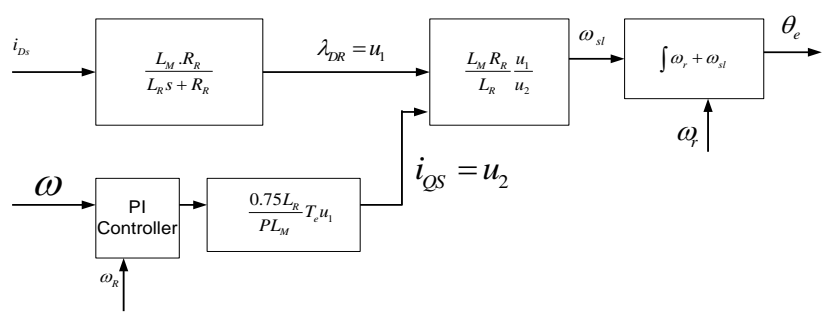

Figure 2. Rotor angle estimation

\section{PROPOSED MODIFIED TYPE 2 NEURO-FUZZY CONTROLLER}

The block diagram of the proposed indirect vectorcontrolled induction motor drive with two-level inverter is as shown in Figure 3. From the field control and speed control the reference values of currents $i_{D S}^{*}$ and $i_{Q S}^{*}$ are obtained and these values are compared with the respective $i_{D S}$ and $i_{Q S}$ currents generated by the transformation of phase currents with the unit vector. From the respective errors, d-axis voltage VDS and q-axis voltage VQS are generated through PI controllers. These voltages are then converted into stationary frame and then given to SVM block.The T2NFC structure with four-layer neural network as shown in Figure 4. To improve the performance of the induction motor drive, the proposed T2NFC is modified by simple algorithm by taking single input as an error i.e. speed and torque against two inputs error and change in error of conventional T2NFC. The third layer parameter is adjusted by tuning to monitor the deviations of control effort. The inputs of the T2NFC are the error in torque and changes of torque, where $T_{e}{ }^{*}$ is the command. The single input torque error due to the difference of desired torque $T_{e}{ }^{*}$ and actual torque $T_{e}$ :

$$
\% e_{w}(t)=\frac{T_{e}^{*}-T_{e}}{T_{e}^{*}} \times 100
$$

Layer 1: The fuzzification layer output equations having nodes of three torque error membership functions as NEGATIVE(N), ZERO(Z) AND POSITIVE(P) torque errors are:

$$
\begin{aligned}
& o_{1}{ }^{1}=A_{M 1}\left(e_{\omega(t)}\right) \\
& o_{2}{ }^{1}=A_{M 2}\left(e_{\omega(t)}\right) \\
& o_{3}{ }^{1}=A_{M 3}\left(e_{\omega(t)}\right)
\end{aligned}
$$


The mathematical membership function is described as:

$$
A_{M j}=e^{\left(-\frac{1}{2}\left(\frac{(x-c)^{2}}{\sigma^{2}}\right)\right)}, j=1,2
$$

where, $c$ and $\sigma$ are the center and width of membership functions.

Layer 2: In this layer, the logic operator is not used to calculate the weight of rules as there is only single input unlike two inputs in conventional T2NFC.

$$
o_{j}^{2}=\overline{w_{J}}=\frac{w_{j}}{w_{1}+w_{2}}, j=1,2
$$

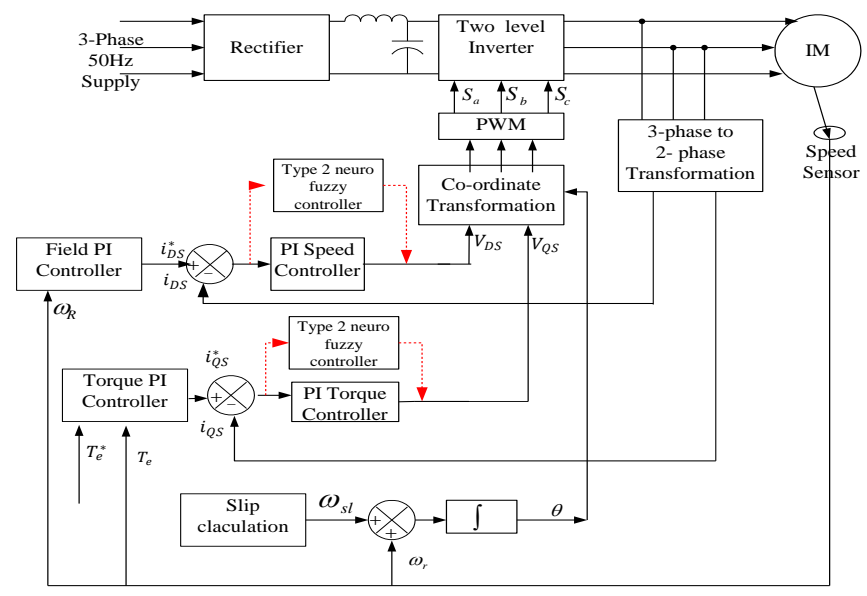

Figure 3. Proposed type 2 neuro-fuzzy controller

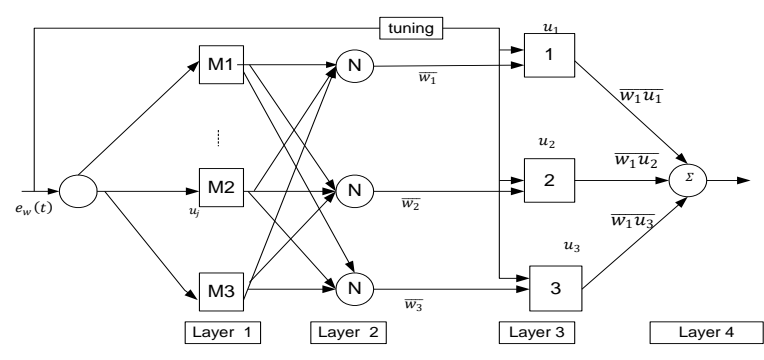

Figure 4. Type 2 neuro-fuzzy system

Layer 3: In this layer, each node with a node function is given by:

$$
o_{j}^{3}=\overline{w_{j}} u_{j}, j=1,2,3
$$

Layer 4: In this layer, every node normalizes the firing strengths of rule that is generated by the type reduction layer:

$$
u_{j}=o_{j}^{4}=\frac{\Sigma w_{j} u_{j}}{\Sigma w_{j}}, j=1,2,3
$$

\section{TWO-INPUT CONVENTIONAL TYPE 2 NEURO- FUZZY CONTROLLER}

The T2NFC architecture design combines a neural networkbased learning algorithms and fuzzy logic with a seven-level neural network architecture, as shown in Figure 5. The two inputs of the T2NFC are the error in torque and changes of torque, where $T_{e}{ }^{*}$ is the command. In this seven-layer architecture, the layer1 represents the inputs; the layer 2 represents fuzzification, layer 3 represents firing, layer 4 represents reduction layer, layer 5 represents normalization, layer 6 represents outputs. A T2NFC are characterized by fuzzy IF-THEN rules.

The parameters in the antecedent and the consequent parts of the rules include type-2 fuzzy values. In the proposed system, the ruleset with fuzzy can be expressed as:

Rule $j(j=1,2--)$ : if $e_{\omega}$ is $m_{1 j}$ and $\Delta e_{\omega} m_{2 j}$ then $y_{j}$ is $\Sigma w_{l k} m_{j}+b_{j}$ where $m_{l j}$ and $m_{2 j}$ are antecedent fuzzy sets and $x_{1 j}, w_{l k}$ and $b_{i}$ are the design parameters estimated in training. Here $y_{i}$ is the output membership function.

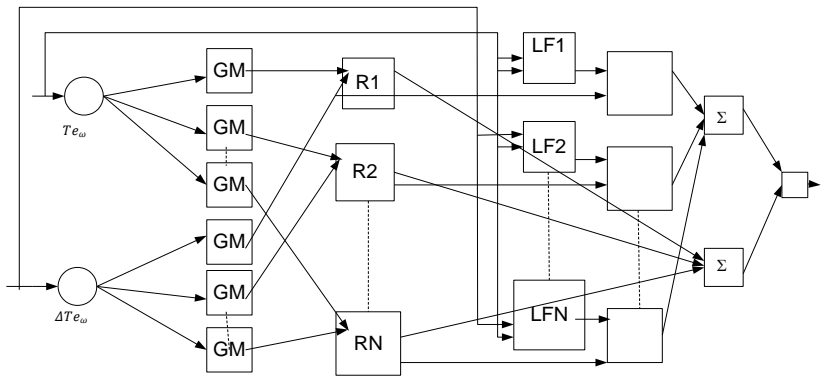

Figure 5. Type 2 neuro-fuzzy system

Layer 1: This layer consists of node membership functions:

$$
\begin{gathered}
o_{j}{ }^{1}=A_{m j 1}\left(e_{\omega}\right), \mathrm{j}=1,2 \\
o_{j}{ }^{1}=A_{m j 2}\left(\Delta e_{\omega}\right), j=1,2
\end{gathered}
$$

where, $A_{m j 1}$ and $A_{m j 2}$ are membership functions. The mathematical membership function is described as:

$$
A_{m j}=e^{\left(-\frac{1}{2}\left(\frac{\left(m_{j}-c\right)^{2}}{\sigma^{2}}\right)\right)}
$$

where, $c$ and $\sigma$ are the center and width of membership functions

Layer 2: In this layer, each node calculates the firing strength of a rule with the smallest error or change in error of two input weights:

$$
\begin{gathered}
o_{j}{ }^{2}=w_{i}=A_{m j 1}\left(e_{\omega}\right) \cdot A_{m j 2}\left(\Delta e_{\omega}\right) \\
=\min \left(A_{m j 1}\left(e_{\omega}\right), A_{m j 2}\left(\Delta e_{\omega}\right)\right), i=1,2 \ldots \ldots 7
\end{gathered}
$$

Layer 3: Every node determines the weight in this layer, which is normalized firing strengths:

$$
o_{j} \quad 3=\overline{w_{J}}=\frac{w_{j}}{w_{1}+w_{2}}, j=1,2
$$

Layer 4: In this layer, each node with a node function is given by:

$$
\begin{gathered}
o_{j}{ }^{4}=\overline{w_{j}} u_{j}=\overline{w_{j}}\left(m_{1 j} e_{\omega}+m_{2 j} \Delta e_{\omega}+r_{i}\right), \\
i=1,2, .7
\end{gathered}
$$


where, $\overline{w_{j}}$ is the output layer of 3 and $m_{1 j}$ is the parameter set.

Layer 5: In this layer, every node normalizes the firing strengths of rule that is generated by the type reduction layer:

$$
o_{j}{ }^{5}=\frac{\Sigma w_{j} u_{j}}{\Sigma w_{j}}, j=1,2 . .7
$$

Layer 6: In this layer, the output is determined:

$$
y_{j}=\sum_{j=1}^{l} m_{j} w_{l j}+b_{i}, j=1 \ldots l
$$

\section{TRAINING ALGORITHM FOR PROPOSED TYPE 2 NEURO-FUZZY CONTROLLER}

The Back Propagation(BP) algorithm is used as part of the proposed Type 2 Neuro-Fuzzy Torque controller that has been tuned automatically by the least square estimation method algorithm is very fast where a gradient descent rule changes the weight with significant features such as positioning of global minimum cost function, quick scaling, better generalization, and reduced computing complexity. The cost function while training type 2 Neuro-fuzzy controller is described as:

$$
E=\frac{1}{2} \sum_{p=1}^{N}\left(u_{p}^{d}-u_{p}\right)^{2}
$$

where, $u_{p}^{d}$ stands for expected output for pth specific section pattern and $u_{p}$ is the actual performance expected by type 2 Neuro-fuzzy controller. $\mathrm{N}$ is the set of training examples for the proposed controller, which is 252 . The data has been trained by the BP algorithm based on the network error $\xi$. The minimized objective function is as follows:

$$
E=\frac{1}{2}\left(T_{e}^{*}-T_{e}\right)^{2}=e^{2}
$$

where, $T_{e}^{*}$ is the reference torque, and $T_{e}$ is estimated torque. To achieve the desired output, it is required to derive the BP parameter rules for instant parameter updates.

$$
\begin{gathered}
x_{i}(l+1)=x i(k)-\eta_{a i} \nabla_{x i} E(l) \\
y_{i}(l+1)=y_{i}(l)-\eta_{b i} \nabla_{y i} E(l) \\
w_{i}(l+1)=w_{i}(l)-\eta_{w i} \nabla_{w i} E(l)
\end{gathered}
$$

where, $\eta$ is The values of $(\mathrm{x}, \mathrm{y})$ are $\left(x, b_{i}\right)$ refers to the ith node. The fixed learning rate of the respective parameters $\left(x_{i}, y_{i}, w_{i}\right)$ and $\left(\nabla_{x i}, \nabla_{y i}, \nabla_{w i}\right)$ is the gradient of cost function $\mathrm{E}$ corresponding to parameters $\left(a_{i}, b_{i}, w_{i}\right)$ defined in the equations:

$$
\begin{aligned}
& \nabla_{a i} E=\frac{\partial E}{\partial e} \frac{\partial e}{\partial T_{e}} \frac{\partial T_{e}}{\partial u} \frac{\partial u}{\partial O_{i}^{1}} \frac{\partial O_{i}^{1}}{\partial a_{i}} \\
& \nabla_{b i} E=\frac{\partial E}{\partial e} \frac{\partial e}{\partial T_{e}} \frac{\partial T_{e}}{\partial u} \frac{\partial u}{\partial O_{i}^{1}} \frac{\partial O_{i}^{1}}{\partial b_{i}}
\end{aligned}
$$

$$
\nabla_{w i} E=\frac{\partial E}{\partial e} \frac{\partial e}{\partial T_{e}} \frac{\partial T_{e}}{\partial u} \frac{\partial u}{\partial w_{i}}
$$

The general differential forms of the above equations are as follows:

$$
\begin{gathered}
\frac{\partial E}{\partial e}=T_{e}^{*}-T_{e} \\
\frac{\partial e}{\partial T_{e}}=-1 \\
\frac{\partial T_{e}}{\partial u}=\text { constant } K
\end{gathered}
$$

For the T2NFC based induction motor drive the value of $\mathrm{K}$ is greater than zero. Other terms for the Eqns. (68)-(70) are evaluated by comparison to Eqns. (49)-(53) as:

$$
\begin{gathered}
\frac{\partial y}{\partial O_{i}^{1}}=\frac{u_{i}(k)}{\sum w_{i}(k)} \\
\frac{\partial O_{i}^{1}}{\partial a_{i}}=\frac{2}{b_{i}(k)} \\
\frac{\partial O_{i}^{1}}{\partial b_{i}}=\frac{1-O_{i}^{1}(k)}{b_{i}(k)} \\
\frac{\partial u}{\partial w_{i}}=\frac{u_{i}(k)}{\sum o_{i}^{2}(k)}
\end{gathered}
$$

Error acceptance is used to establish a stop criterion relevant to the scale of the error. Training ends subsequently the training data error continues within this tolerance. Such errors have been displayed by taking 30 training cycles, which is slightly less than ANN learning.

\section{RESULTS AND DISCUSSION}

\subsection{Performance characteristics of induction motor during starting}

During starting the performance of the motor, as shown in Figure 6, and it shows the high current at the starting is condensed when compared to PI controller. The maximum torque obtained by using PI controller is about $25 \mathrm{~N}-\mathrm{m}$, and T1NFC is $26 \mathrm{~N}-\mathrm{m}$. The torque is significantly improved and it settles at $0.24 \mathrm{~s}$, and ripples in torque is also reduced with T2NFC. Induction motor speed reaches its set point of 1445 $\mathrm{rpm}$ in $0.256 \mathrm{~s}$ with PI controller and $0.24 \mathrm{~s}$ with type-I neurofuzzy controller and $0.24 \mathrm{~s}$ with type 2 Neuro-Fuzzy controller.

\subsection{Steady state performance characteristics}

The stator phase current, torque and rotor speed during steady sate condition as shown in Figure 7. By using the PI controller, the ripples in torque is in between +1.4 to -1.4 , with TINFC is in between +1.2 to -1.2 . and with T2NFC is in between +0.9 to -0.9 . By using T2NFC, the ripples in the stator phase current and torque is reduced. 


\subsection{Response in load torque perturbation}

The induction motor performance during the changes in load torque, as depicted in Figure 8. At a steady-state speed of $1445 \mathrm{rpm}$, from $0.6 \mathrm{~s}$ to $0.8 \mathrm{~s}$ the load torque of $9 \mathrm{~N}-\mathrm{m}$ is applied. During load changes of PI controller at the same instant, it was observed that the use of a type 2 based controller enhances the response in speed by an excellent load perturbation elimination. The torque ripple is minimized as compared to PI and T1NFC leading to less distortion of motor current.
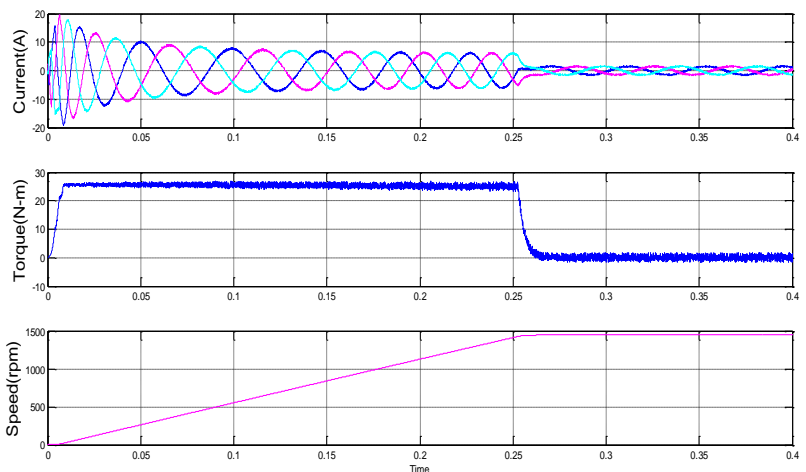

(a) PI controllers
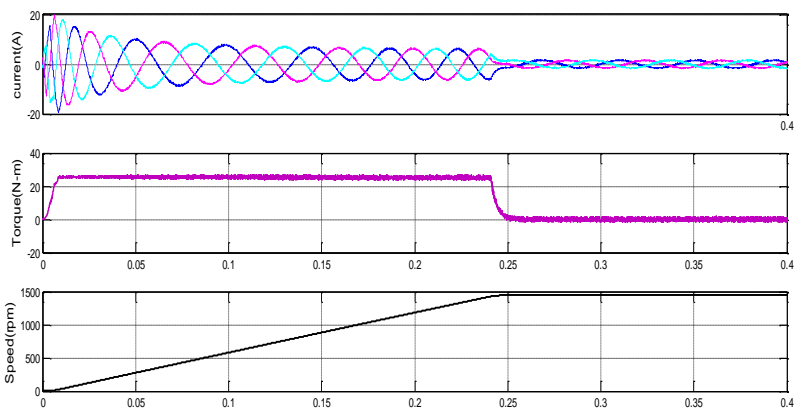

(b) Type 1 Neuro-Fuzzy controller
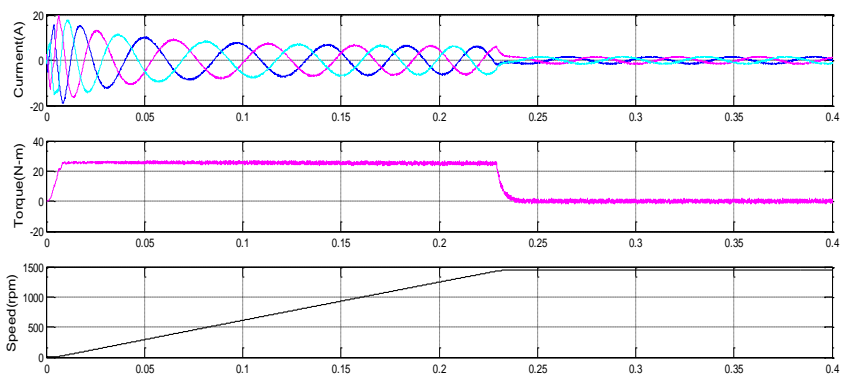

(c) Type 2 Neuro-Fuzzy controller

Figure 6. Induction motor performance characteristics during starting
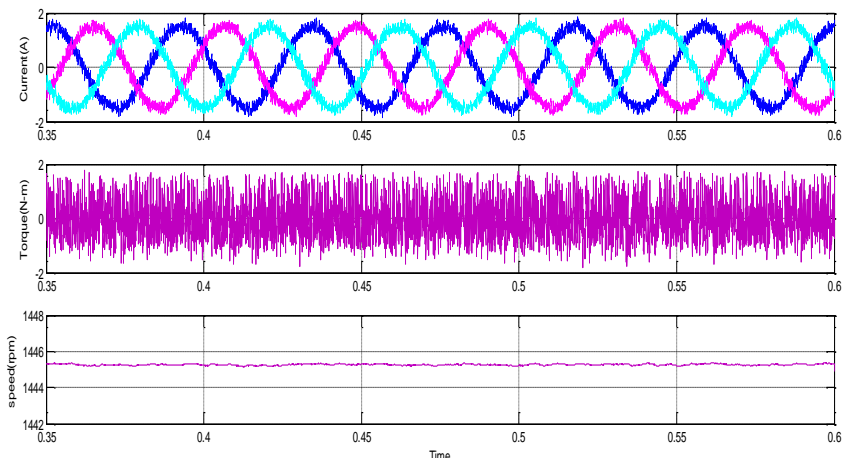

(a) With PI controllers
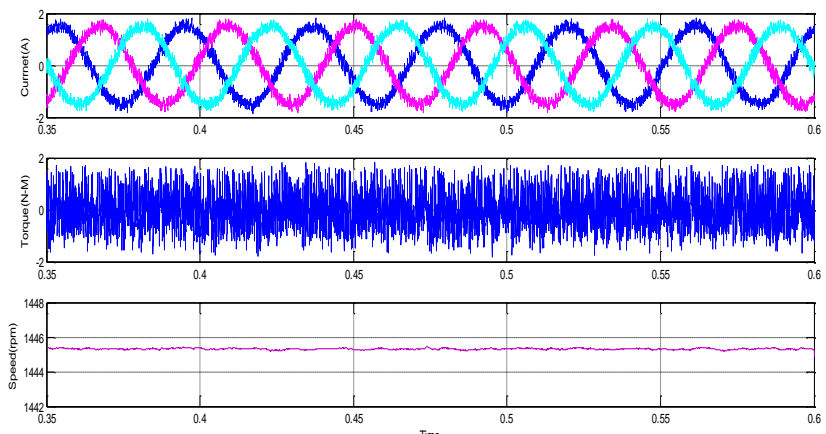

(b) Type 1 Neuro-Fuzzy controller
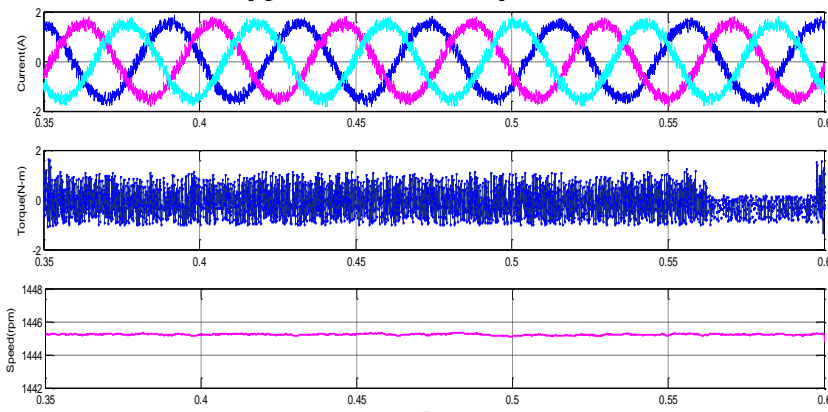

(c) Type 2 Neuro-Fuzzy controller

Figure 7. Steady state performance characteristics
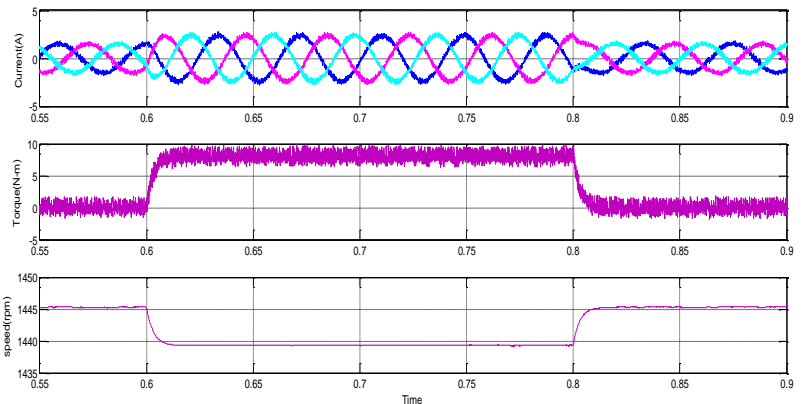

(a) PI controller
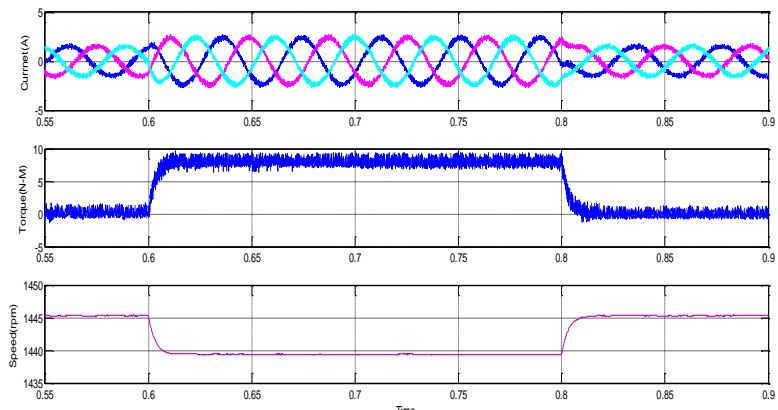

(b) Type 1 Neuro-fuzzy controller
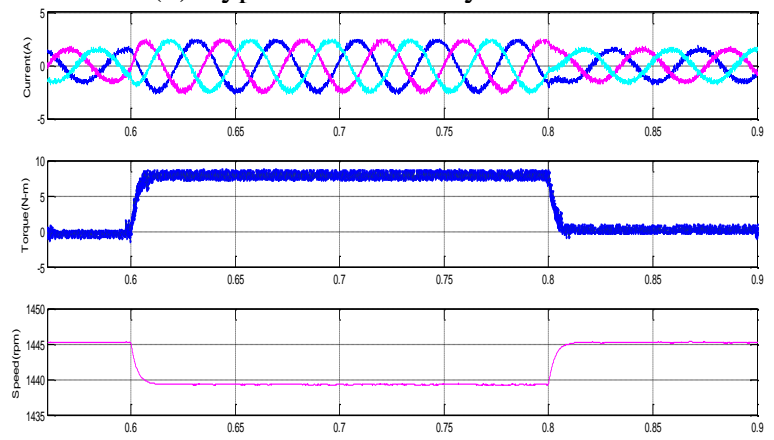

(c) Type 2 Neuro-fuzzy controller

Figure 8. Induction motor performance characteristics during load perturbation 


\section{EXPERIMENTAL VALIDATION}

An experimental prototype was developed in the lab which is shown in Figure 9 , in order to verify the feasibility and performance of the conventional PI, T1NFC and T2NFC of induction motor drive. For the testing and implementation of control algorithms, a dSPACE DS-2812 controller board is used. The control algorithm is initially designed in MatlabSimulink software and afterwards Matlab real time workshop function is used to develop c-code automatically for real time testing. The dSPACE Matlab-Simulink interface with dSPACE DS-2812 enables the hardware to run the control algorithm. Using the master bit input-output, the necessary gate pulses are generated and to interface sensed speed, currents and voltage the Anaolog to Digital converters (ADCs) are used. PI, T1NFC, T2NFC based induction motor drive is simulated and verified under different operating conditions, such as starting, steady-state and step change in load using dSPACE DS-2812 with the experimental setup [19].

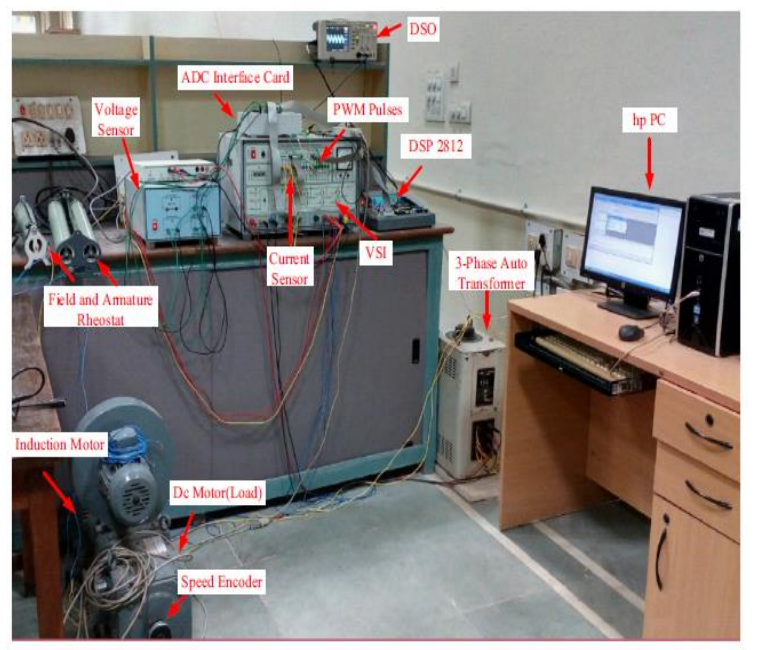

Figure 9. Experimental setup

The starting performance of the IM for PI controller when the reference speed of $1450 \mathrm{rpm}$ is initiated at starting under no-load as shown in Figure 10(a). As the dc-link voltage (Vd) increases from zero to $500 \mathrm{~V}$ by varying the 3-phase autotransformer then the current (ia) and flux are initially build-up and settle to $2.54 \mathrm{~A}$ and $1 \mathrm{~Wb}$, respectively. Consequently, the electromagnetic torque (Te) of IM develops to overcome the inertia and picks up the motor speed $(\mathrm{Nm})$ up to the reference value and it settles at 1.6s. The stator current also arises due to increasing the electromagnetic torque developed by the IM and it is settled at $1.6 \mathrm{~s}$.

The starting performance of the IM with type- 1 neurofuzzy controller as shown in Figure 10(b) .The steady state response is achieved at $1.4 \mathrm{~s}$ during start up with type-1 neuro fuzzy controller, which is faster by $0.2 \mathrm{~s}$ than the PI controller. The torque ripples are reduce by approximately by $28 \%$ compared to the PI controller.

The starting performance of the IM with type- 1 neurofuzzy controller as shown in Figure 10(c). The starting settling time of IMD with T2NFC provides $0.86 \mathrm{~s}$ along with significant improvement in flux and torque ripple than PI controller.The Stator phase current, torque and rotor speed with T2NFC are obtained as 3.96A,27.5 N-m and $1445 \mathrm{rpm}$ respectively.

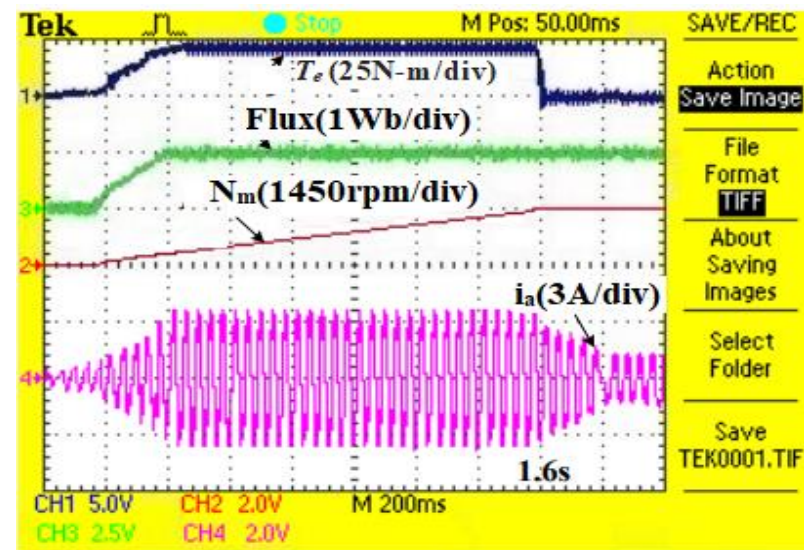

(a) PI controller

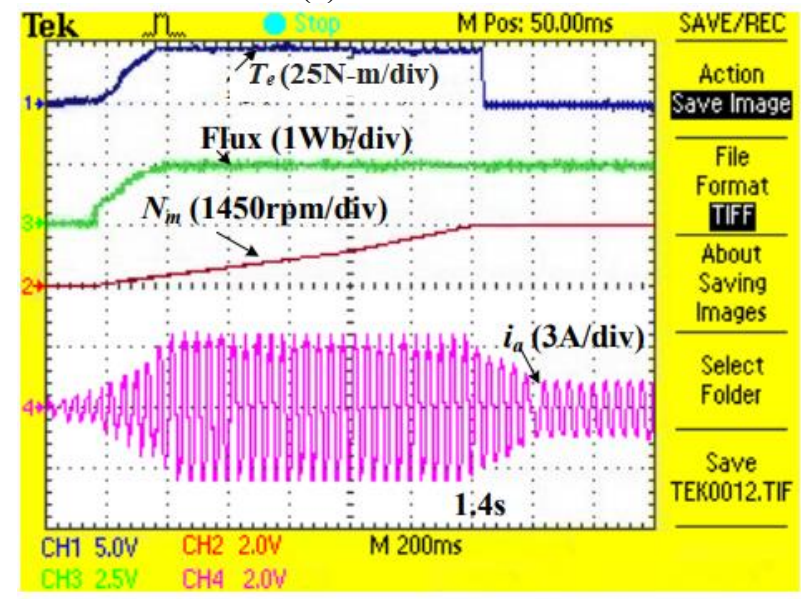

(b) Type 1 Neuro-fuzzy controller

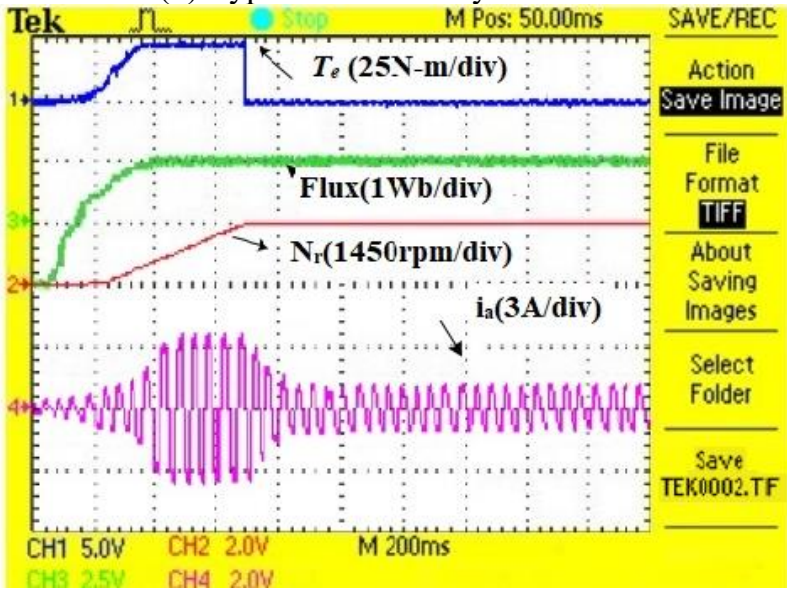

(c) Type 2 Neuro-Fuzzy controller

Figure 10. Induction motor performance during starting

The load $(8 \mathrm{~N} \cdot \mathrm{m})$ is applied and removed to the PI controller of IM drive at 0.2 and $0.7 \mathrm{~s}$, respectively, as shown in Figure 11(a). The electromagnetic torque (Te) rises to $8 \mathrm{~N} \cdot \mathrm{m}$ and falls down to $0 \mathrm{~N} \cdot \mathrm{m}$ because of the load perturbation. The IM decelerates and accelerates to 1440 and $1460 \mathrm{rpm}$ at the abovementioned instants and it settles at 0.5 and $1 \mathrm{~s}$, respectively. Moreover, the current suddenly rises to $2.2 \mathrm{~A}$ at $0.23 \mathrm{~s}$ and again falls down to $1.5 \mathrm{~A}$ at $0.73 \mathrm{~s}$ due to increase and decrease in the load, respectively. However, the flux is maintained constant throughout the operation.

With type-1 neuro-fuzzy controller, the waveforms seem to be the same as PI controller but there is a significant reduction in torque and flux distortion, and less speed fluctuations (speed changes during acceleration and deceleration are 1445 and $1455 \mathrm{rpm}$, respectively) as shown in Figure 11(b). 
The IM speed settles at $0.3 \mathrm{~s}$ and $0.8 \mathrm{~s}$ when the decelerating and accelerating mode of operation is initiated at $0.21 \mathrm{~s}$ and $0.7 \mathrm{~s}$, respectively as shown in Figure 11(c). The speed settling time with T2NFC is faster by $0.1 \mathrm{~s}$ than the T1NFC. In addition, the change in motor speed with T2NFC is \pm 4 rpm only while varying the load whereas it is $\pm 10 \mathrm{rpm}$ for PI controller.The ripples in torque is substantially minimized by the proposed $\mathrm{T} 2 \mathrm{NFC}$, the ripple in torque is in between -0.12 to 0.12 , where as with T1NFC is -0.9 to 0.9 and PI controllers is -1.2 to 1.2. With the proposed $\mathrm{T} 2 \mathrm{NFC}$, the ripple in stator phase current and torque is minimized significantly as compared to T1NFC and PI controllers and smooth speed response is obtained.

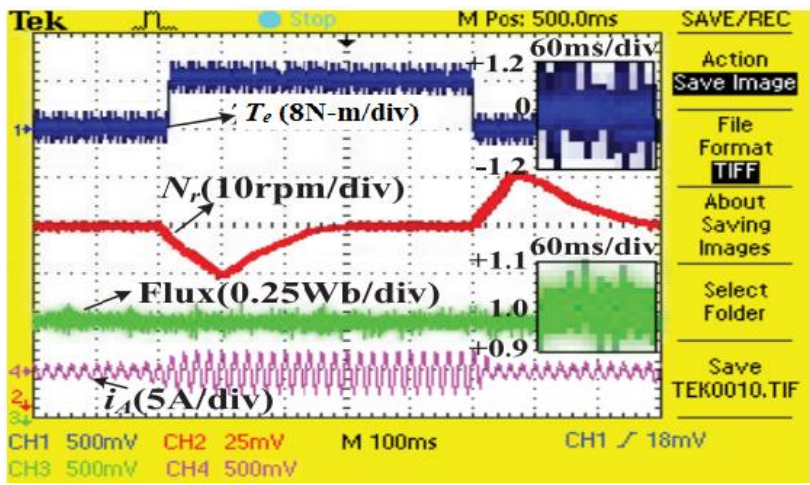

(a) PI Controller

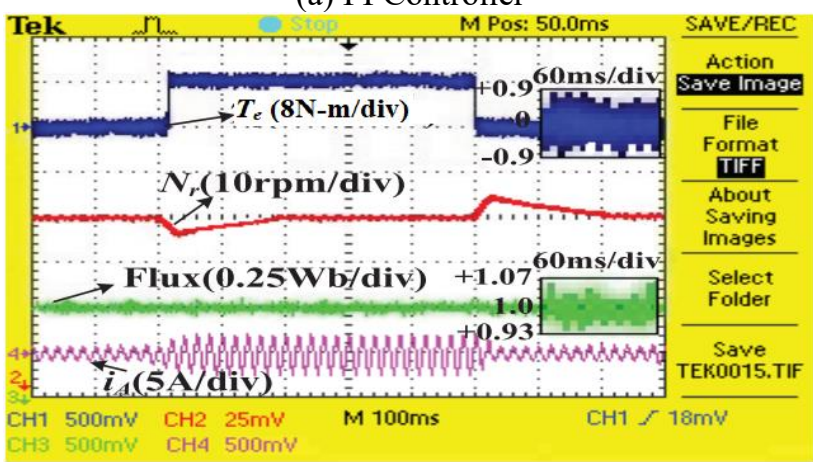

(b) Type 1 Neuro-Fuzzy controller

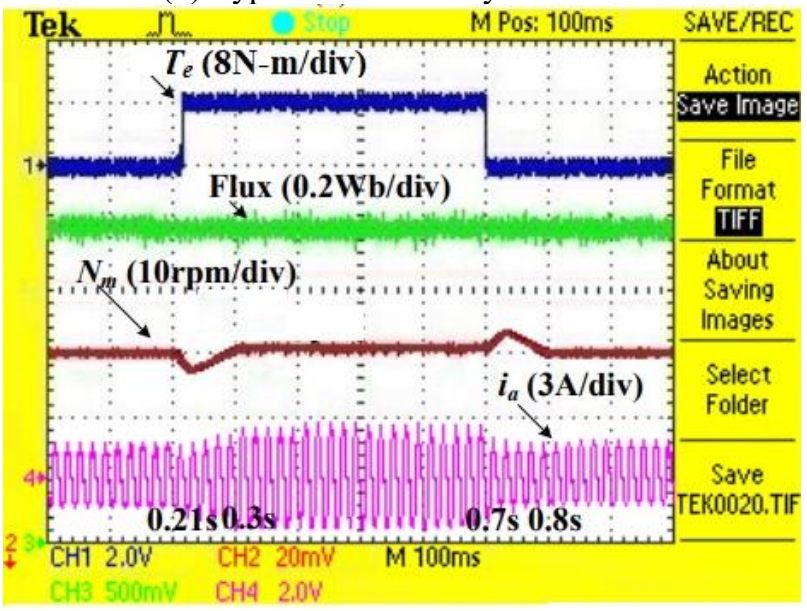

(c) Type 2 Neuro-Fuzzy controller

Figure 11. Steady state and dynamics in load of the T2NFC controlled drive

\section{CONCLUSION}

The T2NFC based IVC of IMD is implemented in real time using experimental prototype system with dSPACE DS 2812 controller. The comparative performances of IMD with
PI,T1NFC and T2NFC under different operating conditions are presented. The PI based indirect vector control gives large ripples in torque and due to this; the time taken to reach steady state response of the induction motor is more at various operating regions. T1NFC is replaced with PI controller to get better dynamic performance of the induction motor. Due to the limitations of T1NFC, the performance of the motor is not considerably improved. Furthermore, T2NFC is replaced instead of T1NFC to get fast dynamic response. It is observed that during the starting condition with type 2 neuro fuzzy controller, the high starting current is reduced and the torque is increases up to $4 \%$ due to this the speed reaches quickly as compared to the PI and T1NFC controllers. During steady state condition, the current ripple is less due that the torque ripple is reduced by $33 \%$ and speed oscillations is less as compared with T1NFC controller. During the step change load torque, the overall ripple content is reduced as compared to the conventional PI and T1NFC controllers. In comparison with PI and T1NFC torque controllers, the performance of a drive under different operating conditions is enhanced with T2NFC torque controllers.

Future work: The type-2 Gaussian membership functions with uncertain standard deviation are used in the proposed method. As a future work, the extension of the proposed method to other types of membership functions like Gaussian type-2 membership functions with uncertain centres, Elliptic type- $2 \mathrm{MFs}$ and so on are some interesting topics to be investigated.

\section{REFERENCES}

[1] Harnefors, L. (2001). Design and analysis of general rotor-flux-oriented vector control systems. IEEE Transactions on Industrial Electronics, 48(2): 383-390. https://doi.org/10.1109/41.915417

[2] Khambadkone, A.M., Holtz, J. (1991). Vector-controlled induction motor drive with a self-commissioning scheme. IEEE Transactions on Industrial Electronics, 38(5): 322327. https://doi.org/10.1109/41.97551

[3] Acevedo, G., Vargas, N., Hernando, G.M., Torres, C., Jairo, J. (2012). Design of rotor flux oriented vector control systems for induction motor. In Proceedings of the 7 th International Power Electronics and Motion Control Conference, pp. 1384-1388. https://doi.org/10.1109/IPEMC.2012.6259010

[4] Krishnan, R. (2001). Electric motor drives: Modeling, Analysis, and Control. Pearson.

[5] Arulmozhiyal, R., Baskaran, K., Manikandan, R. (2011). A fuzzy based PI speed controller for indirect vector controlled induction motor drive. In India International Conference on Power Electronics 2010 (IICPE2010), pp. 1-7. https://doi.org/10.1109/IICPE.2011.5728102

[6] Durgasukumar, G., Pathak, M.K. (2012). Neuro-fuzzybased torque ripple reduction and performance improvement of VSI fed induction motor drive. International Journal of Bio-Inspired Computation, 4(2): 63-72. https://doi.org/10.1504/IJBIC.2012.047174

[7] Sukumar, D., Jithendranath, J., Saranu, S. (2014). Threelevel inverter-fed induction motor drive performance improvement with neuro-fuzzy space vector modulation. Electric Power Components and Systems, 42(15): 16331646. https://doi.org/10.1080/15325008.2014.927022

[8] Durgasukumar, G., Pathak, M.K. (2012). Comparison of 
adaptive Neuro-Fuzzy-based space-vector modulation for two-level inverter. International Journal of Electrical Power \& Energy Systems, 38(1): 9-19. https://doi.org/10.1016/j.ijepes.2011.10.017

[9] Giribabu, D., Vardhan, R.H., Prasad, R.R. (2016). Multi level inverter fed indirect vector control of induction motor using type 2 fuzzy logic controller. In 2016 International Conference on Electrical, Electronics, and Optimization Techniques (ICEEOT), pp. 2605-2610. https://doi.org/10.1109/ICEEOT.2016.7755164

[10] Sathishkumar, H., Parthasarathy, S.S. (2017). A novel neuro-fuzzy controller for vector controlled induction motor drive. Energy Procedia, 138: 698-703. https://doi.org/10.1016/j.egypro.2017.10.203

[11] Mishra, R.N., Mohanty, K.B. (2016). Real time implementation of an ANFIS-based induction motor drive via feedback linearization for performance enhancement. Engineering Science and Technology, an International Journal, 19(4): 1714-1730. https://doi.org/10.1016/j.jestch.2016.09.014

[12] Ramesh, T., Panda, A.K., Kumar, S.S. (2013). Type-1 and type-2 fuzzy logic speed controller based high performance direct torque and flux controlled induction motor drive. In 2013 Annual IEEE India Conference (INDICON), pp. $1-6$. https://doi.org/10.1109/INDCON.2013.6725947

[13] Durgasukumar, G., Abhiram, T., Pathak, M.K. (2012). TYPE-2 fuzzy based SVM for two-level inverter fed induction motor drive. In 2012 IEEE 5th India International Conference on Power Electronics (IICPE), pp. 1-6. https://doi.org/10.1109/IICPE.2012.6450468
[14] Venkataramana Naik, N., Singh, S.P. (2014). Improved torque and flux performance of type-2 fuzzy-based direct torque control induction motor using space vector pulsewidth modulation. Electric Power Components and Systems, 42(6): 658-669. https://doi.org/10.1080/15325008.2013.871608

[15] Naik, N.V., Singh, S.P. (2012). A novel type-2 fuzzy logic control of induction motor drive using space vector PWM. In 2012 Annual IEEE India Conference (INDICON), pp. 1142-1147. https://doi.org/10.1109/INDCON.2012.6420789

[16] Masumpoor, S., Khanesar, M.A. (2015). Adaptive sliding-mode type-2 neuro-fuzzy control of an induction motor. Expert Systems with Applications, 42(19): 66356647. https://doi.org/10.1016/j.eswa.2015.04.046

[17] Mishra, R.N., Mohanty, K.B. (2017). Implementation of feedback-linearization-modelled induction motor drive through an adaptive simplified neuro-fuzzy approach. Sādhanā, 42(12): 2113-2135. https://doi.org/10.1007/s12046-017-0741-6

[18] Mishra, R.N., Mohanty, K.B. (2018). Design and implementation of a feedback linearization controlled IM drive via simplified neuro-fuzzy approach. IETE Journal of Research, 64(2): 209-230. https://doi.org/10.1080/03772063.2017.1351321

[19] Pakkiraiah, B., Sukumar, G.D. (2017). Enhanced performance of an asynchronous motor drive with a new modified adaptive Neuro-Fuzzy inference system-based MPPT controller in interfacing with dSPACE DS-1104. International Journal of Fuzzy Systems, 19(6): 19501965. https://doi.org/10.1007/s40815-016-0287-5 